\title{
Volume de água armazenado no tanque de bromélias, em restingas da costa brasileira
}

\author{
Luciana Cogliatti-Carvalho ${ }^{1}$, Thereza Christina Rocha-Pessôa ${ }^{1}$, André Felippe Nunes-Freitas ${ }^{2}$ \\ e Carlos Frederico Duarte Rocha ${ }^{1,3}$
}

Recebido em 21/11/2007. Aceito em 11/05/2009

\begin{abstract}
RESUMO - (Volume de água armazenada no tanque de bromélias, em restingas da costa brasileira). Muitas espécies de bromélias armazenam água da chuva em seu interior, sendo esta característica resultado da distribuição espiralada de suas folhas, que formam pequenos tanques. O objetivo deste estudo foi avaliar e comparar o volume de água efetivamente armazenado e o volume máximo que pode ser armazenado no tanque de diferentes espécies de bromélias de 13 restingas brasileiras. Em cada restinga, em 100 plots de $100 \mathrm{~m}^{2}$ cada, registramos as espécies de bromélias-tanque, os parâmetros morfométricos e o volume efetivo e máximo em 20 indivíduos de cada espécie. Encontramos 32 espécies de bromélias-tanque, para as quais medimos o volume máximo e o volume efetivo de água armazenado. Em 59.007 rosetas, estimamos o volume máximo em 44.388 litros e medimos 17.000 litros de água efetivamente armazenados. Encontramos diferenças interespecíficas nos volumes máximo e efetivamente reservado de água, na biomassa, no número de folhas e no volume do cone da planta. Aechmea aquilega, A. blanchetiana e Hohenbergia castelanosii tiveram os maiores volumes efetivos. Somente $A$. nudicaulis e Billbergia amoena diferiram entre suas populações em todos os parâmetros analisados. As restingas de Maricá, Prado, Trancoso e Jurubatiba tiveram os maiores volumes de água.ha ${ }^{-1}$ armazenada nas bromélias-tanque. $\mathrm{O}$ volume máximo de água estimado para as bromélias-tanque variou entre espécies devido a diferenças na forma e no tamanho das bromélias.
\end{abstract}

Palavras-chave: Bromeliaceae, bromélia-tanque, disponibilidade de água livre, arquitetura foliar

\begin{abstract}
Water volume stored in bromeliad tanks in Brazilian restinga habitats). Many bromeliad species store rain water in tanks, as a result of the spiraled distribution of their leaves. The aim of this study was to evaluate how much water is stored and what is the maximum volume of water possible to be stored in different tank-bromeliad species in 13 different Brazilian restingas. The species were recorded in 100 plots of $100 \mathrm{~m} 2$, in each restinga habitat. For each bromeliad species, the effective and the maximum water stored in the tanks were measured. We found 32 tank-bromeliad species and 59,007 bromeliad rosettes, with a maximum volume estimated in 44,388 liters, and approximately 17,000 liters of effective water stored. We found interspecific difference in effective and maximum volume of water stored. Aechmea aquilega, A. blanchetiana and Hohenbergia castelanosii had the highest effective water volume stored in their tanks. Only A. nudicaulis and Billbergia amoena showed differences among their populations in all analyzed parameters. The restingas of Maricá, Prado, Trancoso and Jurubatiba had the highest volumes.ha-1 of water stored inside bromeliad tanks. The maximum water volume stored in the bromeliad tanks varied among species due to morphological differences in shape and size parameters.
\end{abstract}

Key words: Bromeliaceae, tank bromeliad, free water availability, rosette shape

\section{Introdução}

Algumas famílias do reino vegetal possuem a capacidade de interceptar e de acumular água e matéria orgânica em decomposição, mas em nenhuma outra família tal característica ocorre de forma tão eficiente quanto na família Bromeliaceae (Benzing \& Renfrow 1974). A capacidade de armazenar água está relacionada com a forma de cone invertido e com a disposição espiralada e imbricada das folhas das bromélias (Picado 1913; Benzing \& Renfrow 1974; Benzing 1980; Rocha et al. 2004), resultado de um processo evolutivo que possibilitou a estas espécies adaptarem-se e sobreviverem em habitats com as mais variadas condições ambientais (Medina 1974; Benzing 1980; Zotz \& Thomas 1999).

As espécies-tanque de Bromeliaceae são integrantes de elevada importância para os ecossistemas em que estão inseridas, principalmente naqueles onde há pouca água livre disponível, tais como as restingas (Picado 1913; Lopez 1998; Rocha et al. 2000; 2004). Nestas formações, as bromélias possuem um papel importante como facilitadoras para o estabelecimento de outras espécies vegetais (Zaluar \& Scarano 2000) e como incrementadoras da diversidade biológica, por promoverem recursos a diferentes grupos de animais (Rocha et al. 2000; 2004). Segundo Zotz \& Thomas (1999), a importância das bromélias-tanque como fonte de água e de umidade pode ser melhor compreendida se fatores como a capacidade de retenção de água, a geometria e o tamanho da roseta, como área de captação de água da chuva, forem levados em consideração.

A água efetivamente encontrada no interior do vaso de bromélias-tanque, em qualquer momento, é, basicamente, função de dois elementos: i) a arquitetura da planta, que determina a eficiência na capacidade de reserva e afeta a taxa de evaporação da água retida e, ii) o efeito do clima local, que determina a quantidade de chuva, a taxa de insolação e a taxa de evaporação (Zotz \& Thomaz 1999; Rocha et al. 2004). Dessa forma, apesar da roseta da bromélia possuir uma capacidade máxima de armazenamento de água em seu interior (volume máximo armazenável), este é afetado pelas condições climáticas, sofrendo uma redução para o volume efetivamente existente no seu interior (volume efetivo armazenado). As variações inter e intra-específicas na estrutura e na arquitetura das bromélias-tanque podem resultar em diferenças no volume de água armazenado em seu vaso (Richardson 1999). Desta forma, é de se esperar que o volume máximo de água varie entre espécies em um mesmo habitat e entre populações de uma determinada espécie em diferentes habitats.

\footnotetext{
Universidade do Estado do Rio de Janeiro, Instituto de Biologia Roberto Alcantara Gomes, Rio de Janeiro, RJ, Brasil

2 Universidade Federal Rural do Rio de Janeiro, Instituto de Florestas, Serópédica, RJ, Brasil

3 Autor para correspondência: cfdrocha@uerj.br
} 
As restingas são caracterizadas por longas faixas de depósitos arenosos marinhos localizados na costa leste do Brasil (Rizzini 1979; Araújo 1992), cuja flora possui uma variedade de adaptações às condições de intensa salinidade e radiação solar (Araújo 1992). A vegetação característica é herbáceo-arbustiva e arbórea, bastante influenciada pela Floresta Atlântica (Cerqueira 2000). Por estarem inseridas no ecossistema de Floresta Atlântica (Morelatto 2000), o clima das restingas é classificado como tropical úmido (Araújo 1992), embora grande parte das chuvas caia sobre o solo e percole para o lençol freático. Como resultado, as restingas possuem uma taxa de água livre disponível no solo relativamente baixa (Zaluar \& Scarano 2000; Scarano 2002).

Neste estudo, para avaliarmos em que extensão o volume de água armazenado por bromélias-tanque varia tanto entre espécies quanto entre populações vivendo em diferentes restingas, medimos o volume de água máximo e efetivo que cada espécie de bromélia-tanque pode armazenar. Procuramos responder às seguintes questões: i) Qual a densidade de bromélias-tanque nas restingas estudadas?; ii) Quais os volumes máximo e efetivo armazenados por cada espécie de bromélia em cada restinga?; iii) As espécies diferem significativamente nos volumes máximos de água?; iv) Existe diferença no volume máximo de água armazenado pelas bromélias-tanque entre populações?; v) Qual proporção média do volume máximo é efetivamente armazenado por cada espécie de bromélia?; vi) Existem diferenças significativa na proporção do volume máximo que é efetivamente armazenado entre as espécies de bromélia-tanque?

\section{Material e métodos}

Realizamos a amostragem do volume de água armazenado no vaso de bromélias-tanque em 13 diferentes restingas da costa brasileira (Tab.1).

Tabela 1. Localização geográfica, formações vegetais amostradas, pluviosidade e respectivas referências bibliográficas das informações apresentadas.

\begin{tabular}{|c|c|c|c|c|}
\hline Restingas & Localização Geográfica & $\begin{array}{l}\text { Pluviosidade } \\
\text { média }(\mathrm{mm})^{*}\end{array}$ & Formações Vegetais Amostradas & Referência \\
\hline \multicolumn{5}{|l|}{ Rio de Janeiro } \\
\hline Praia do Sul & $23^{\circ} 11^{\prime} \mathrm{S} 44^{\circ} 12^{\prime} \mathrm{O}$ & $2.200,0$ & $\begin{array}{l}\text { Psamófila reptante de anteduna; fechada de } \\
\text { pós-praia e floresta de restinga. }\end{array}$ & $\begin{array}{l}\text { Araújo \& Oliveira } 1988 \\
\text { Nunes-Freitas et al. } 2006\end{array}$ \\
\hline Grumari & $23^{\circ} 02^{\prime} \mathrm{S} 43^{\circ} 31^{\prime} \mathrm{O}$ & $1.116,4$ & $\begin{array}{l}\text { Halófila-psamófila reptante; fechada de pós- } \\
\text { praia; arbustiva-aberta; arbustiva- fechada e } \\
\text { mata de restinga. }\end{array}$ & Silva \& Pinheiro 2007 \\
\hline Maricá & $22^{\circ} 57^{\prime} \mathrm{S} 42^{\circ} 51^{\prime} \mathrm{O}$ & $1.027,2$ & $\begin{array}{l}\text { Halófila-psamófila reptante, fechada de pós- } \\
\text { praia, vegetação arbustiva, restinga aberta, } \\
\text { vegetação lenhosa e esclerofila. }\end{array}$ & $\begin{array}{l}\text { Silva \& Somner } 1984 \\
\text { Silva \& Oliveira } 1989\end{array}$ \\
\hline Massambaba & $22^{\circ} 56^{\prime} \mathrm{S} 42^{\circ} 12^{\prime} \mathrm{O}$ & 750,0 & $\begin{array}{l}\text { Halófila-psamófila reptante, fechada de pós- } \\
\text { praia, arbustiva de Clusia e arbustiva fechada } \\
\text { de Myrtaceae. }\end{array}$ & Rocha-Pessôa et al. 2008 \\
\hline Jurubatiba & $22^{\circ} 17^{\prime} \mathrm{S} 41^{\circ} 41^{\prime} \mathrm{O}$ & $1.300,0$ & $\begin{array}{l}\text { Halófila-psamófila reptante, fechada de pós- } \\
\text { praia, arbustiva aberta de Clusia, arbustiva } \\
\text { aberta de Ericaceae e mata periodicamente } \\
\text { inundada. }\end{array}$ & $\begin{array}{l}\text { Freitas et al. } 2000 \\
\text { Cogliatti-Carvalho et al. } 2001\end{array}$ \\
\hline Grussaí & 21o 44’ S 41o 01' O & $1.000,0$ & $\begin{array}{l}\text { Formação praial graminóide, formação praial } \\
\text { com moitas, formação de Clusia e formação } \\
\text { Mata de Restinga. }\end{array}$ & Assumpção \& Nascimento, 2000 \\
\hline \multicolumn{5}{|l|}{ Espírito Santo } \\
\hline Praia das Neves & $21015^{\prime} \mathrm{S} 40 \mathrm{o} 57^{\prime} \mathrm{O}$ & $1.100,0$ & $\begin{array}{l}\text { Halófila-psamófila reptante; fechada de } \\
\text { pós-praia; arbustiva semi-aberta com moitas } \\
\text { esparças e arbóreo-arbustiva fechada. }\end{array}$ & Presente estudo. \\
\hline Setiba & 20o 34’ S, 40o 26’ O & $1.400,0$ & $\begin{array}{l}\text { Halófila-psamófila reptante, pós-praia, aberta } \\
\text { de Clusia, restinga aberta de Ericaceae, mata } \\
\text { de Myrtaceae e mata seca. }\end{array}$ & Pereira, 1990 \\
\hline Guriri & $18 \mathrm{o} 40^{\prime} \mathrm{S}, 39 \mathrm{o} 44^{\prime} \mathrm{O}$ & $1.500,00$ & $\begin{array}{l}\text { Halófila-psamófila reptante; zona de } \\
\text { Alagoptera arenaria; fechada de pós-praia; } \\
\text { aberta de Clusia; arbóreo-arbustiva fechada. }\end{array}$ & Presente estudo. \\
\hline \multicolumn{5}{|l|}{ Bahia } \\
\hline Prado & 17 o $18^{\prime}$ ' 39 o 13 ' O & $1.200,0$ & $\begin{array}{l}\text { Halófila-psamófila reptante; fechada de pós- } \\
\text { praia; vegetação herbácea, arbustiva aberta } \\
\text { e abórea. }\end{array}$ & Presente estudo. \\
\hline Trancoso & $16039^{\prime}$ 's 39o 05' O & $1.300,0$ & $\begin{array}{c}\text { Halófila-psamófila reptante; fechada de } \\
\text { pós-praia; área aberta de Clusia e mata de } \\
\text { restinga. }\end{array}$ & Presente estudo. \\
\hline Abaeté & $12056^{\prime} \mathrm{S}, 38021^{\prime} \mathrm{O}$ & $1.528,0$ & $\begin{array}{c}\text { Vegetação reptante; vegetação arbustiva } \\
\text { aberta e mata de restinga. }\end{array}$ & Presente estudo. \\
\hline Baixio & 11 o $53^{\prime} \mathrm{S}, 37$ o $38^{\prime} \mathrm{O}$ & $1.157,0$ & $\begin{array}{c}\text { Vegetação fechada, aberta de moitas, } \\
\text { formação de dunas, encraves interdunas e } \\
\text { mata de restinga. }\end{array}$ & Presente estudo. \\
\hline
\end{tabular}


Em cada restinga, medimos o volume efetivo ( $\mathrm{m} \ell$.roseta-1) de água armazenada no tanque de 20 rosetas e o volume máximo em 10 rosetas de cada uma das espécies de bromélia-tanque encontradas. Amostramos plantas de diferentes tamanhos para obter o máximo de variância na arquitetura de cada espécie, mas sempre a partir de um tamanho mínimo em que o reconhecimento da espécie fosse possível. As amostragens em todas as restingas foram realizadas durante a estação de chuvas (de novembro de 1999 a março de 2000 e em fevereiro de 2001).

Para medir o volume efetivo de água armazenada, retiramos cuidadosamente a bromélia do substrato e, após removermos o folhiço que se encontrava depositado entre as folhas, vertemos a água contida no interior da bromélia em um saco plástico de $100 \ell$, passando-a através de uma peneira para remover eventuais detritos. Posteriormente, medimos este volume efetivo de água (VE) com o uso de provetas de plástico com capacidades de $1,0,5$ ou 0,1 . Já o volume máximo (VM) de água que cada espécie de bromélia seria capaz de armazenar foi medido despejando-se água de uma proveta graduada com precisão de $10 \mathrm{~m} \ell$ para o interior das rosetas, até o nível em que o vaso ficasse completamente cheio de água, sem que esta vazasse da bromélia.

Medimos a altura $(\mathrm{em} \mathrm{cm})$ e o diâmetro $(\mathrm{em} \mathrm{cm})$ com uma fita métrica (com precisão de $1 \mathrm{~mm}$ ) e contamos o número de folhas das rosetas que foram utilizadas para medir o volume efetivo. A altura da planta foi medida desde a base da bromélia até o ápice da folha mais alta. O diâmetro foi medido a partir do ápice da folha mais externa até o ápice foliar do extremo oposto. Para calcular o volume do cone $\left(\mathrm{em}^{3} \mathrm{~cm}^{3}\right)$, utilizamos a fórmula do volume do cone: $\mathrm{V}=\pi \cdot \mathrm{r}^{2} \cdot \mathrm{h} / 3(\mathrm{r}=\mathrm{raio} ; \mathrm{h}=$ altura $)$. Em campo, medimos as massas no (peso fresco) (em g.roseta ${ }^{-1}$ ) com dinamômetros Pesola de 50, $500 \mathrm{~g}$ ou $2 \mathrm{~kg}$ de capacidade, com precisões de 1,5 e $50 \mathrm{~g}$, respectivamente. Para as bromélias de maior porte, foi utilizada uma balança com capacidade de $10 \mathrm{~kg}$ e precisão de $100 \mathrm{~g}$.

Obtivemos o volume efetivo médio (VEM) das espécies por meio da fórmula: $\operatorname{VEM}(\mathrm{m} \ell$.roseta-1) $=\Sigma v e \cdot n-1$; e o volume máximo médio por espécie $(\mathrm{VMM})$, pela fórmula: $\mathrm{VMM}(\mathrm{m} \ell$ roseta- 1$)=\Sigma v m \cdot n-1$, onde $n$ é o número total de rosetas da espécie de bromélia, ve e $v m$ os volumes de água efetivo e máximo, respectivamente, medidos nas rosetas da espécie. $\mathrm{O}$ volume efetivo da espécie em cada restinga (VER) foi obtido pela fórmula: VER $(\ell$.ha-1 $)=\Sigma\left(v e_{2}\right)$, e o volume máximo de água reservado por cada espécie em cada restinga (VMR) foi calculado pela fórmula: VMR ( $\ell$.ha-1) $=\Sigma\left(v m_{2}\right)$, onde $v e_{2}$ e $v m_{2}$ são, respectivamente, os volumes de água efetivo e máximo armazenados nas rosetas de cada espécie da restinga.

Para avaliar a proporção média da água que é efetivamente armazenada (VE) pelas espécies de bromélia em relação à capacidade total de água que pode ser armazenada (VM), dividimos os valores de VE pelos valores de VM (VE.VM-1) encontrados nas mesmas rosetas para cada espécie. Relacionamos os valores de VER, VMR e VMM com a pluviosidade média de cada restinga através de análise de correlação de Pearson (Zar 1999). Como valores de porcentagens possuem uma distribuição mais próxima da binomial do que da normal, tranformamos estes valores para o arcoseno da raiz quadrada antes de calcularmos a média por espécie, de forma a normalizar os dados (Zar 1999).

Avaliamos possíveis diferenças entre as espécies de bromélias-tanque no VE, no VM, na proporção VE.VM-1, na biomassa, no número de folhas e no volume do cone, utilizamos análise de variância para um fator (ANOVA), seguida do teste a posteriori de Tukey, para identificar quais espécies diferiam entre si para cada um destes parâmetros (valores em logaritmo). Para analisarmos em que grau as diferentes espécies de bromélia se agrupam como função das variáveis morfométricas e de medidas do cone, empregamos análise de componentes principais (PCA) (ter Braak 1987; 1995; Legendre \& Legendre 1998), utilizando as variáveis: volume máximo, biomassa, número de folhas e volume do cone. Apesar das espécies Aechmea aquilega, Hohenbergia castelanosii e Portea silveirae terem sido amostradas nas restingas estudadas, estas foram retiradas das análises devido ao reduzido número de indivíduos amostrados.

Testamos em que extensão as restingas estudadas diferiam nos parâmetros supracitados, utilizamos ANOVA seguida do teste de Tukey, com as espécies que ocorreram em mais de uma restinga, identificando eventuais diferenças entre as populações (Zar 1999).

Para analisar em que grau o aumento na densidade de bromélias-tanque em cada restinga resultaria em um aumento no volume total de água livre armazenado no vaso das bromélias, utilizamos análise de regressão simples (Zar 1999).

\section{Resultados}

Estimamos uma densidade de $5363 \pm 3842$ rosetas por hectare, distribuídas nas 13 restingas estudadas. Nenhuma roseta foi encontrada sem água em seu interior. Medimos um volume efetivo total de $288,9 \ell$ de água reservados em 1.138 rosetas de bromélias-tanque de 32 espécies (Tab. 2) e $377,1 \ell$ de volume máximo em 553 rosetas.

Os parâmetros volumétricos e morfológicos para cada uma das espécies, mostram que Aechmea aquilega, A. blanchetiana, H. castelanosii e Quesnelia quesneliana apresentaram os maiores valores de volume máximo e de biomassa dentre as espécies encontradas (Tab. 3). Já Neoregelia sarmentosa, B. pyramidalis, B. amoena, E. ambigua e A. itapoana apresentaram menor capacidade máxima de reserva de água, possivelmente por serem constituídas por um menor número de folhas e possuírem menor biomassa (Tab. 3). Além das espécies listadas na Tab. 3, outras espécies de bromélia-tanque foram encontradas nas restingas estudadas, cujos parâmetros não foram medidos, ou por limitações devidas ao elevado tamanho da espécie (Aechmea sphaerocephala e Hohenbergia salzmanii), ou por ocorrerem apenas em áreas de Unidade de Conservação, onde existem restrições de atividades para a manipulação das plantas (A. ramosa, Billbergia euphemiae e Edmundoa lindenii), ou ainda pelo número reduzido (apenas uma) de rosetas encontradas da espécie nas restingas estudadas ( $A$. guarapariensis, Vriesea gigantea e V. rodigasiana).

Apenas as populações de $A$. nudicaulis e de $B$. amoena diferiram nos volumes de água efetivo e máximo reservado, na biomassa, no número de folhas, no volume do cone e na proporção VE.VM-1 entre as restingas amostradas (Tab. 4). As populações de $V$. procera estudadas ao longo da costa não diferiram apenas na proporção $\mathrm{VE} . \mathrm{VM}^{-1}$, e as populações de A. blanchetiana e $N$. pascoaliana não diferiram em nenhum dos parâmetros analisados.

Os valores de VER (ANOVA, $\mathrm{N}=1130 ; \mathrm{R}^{2}=0,339$; $\left.\mathrm{F}_{12,1117}=47,705 ; \mathrm{P}<0,001\right)$, bem como os de VMR (ANOVA, $\mathrm{N}=545 ; \mathrm{R}^{2}=0,185 ; \mathrm{F}_{12.532}=10,093 ; \mathrm{P}<$ $0,001)$ diferiram significativamente para as treze restingas estudadas (Tab. 5).

As espécies diferiram significativamente quanto ao volume de água efetivo (VE) (ANOVA; $\mathrm{N}=1130$; R2 = 0,313; $\mathrm{P}<0,001$ ) e máximo (VM) (ANOVA; $\mathrm{N}=545 ; \mathrm{R} 2$ $=0,359 ; \mathrm{P}<0,001)$, quanto à proporção VE.VM-1 (ANO$\mathrm{VA} ; \mathrm{N}=545 ; \mathrm{R} 2=0,315 ; \mathrm{P}<0,001)$, e quanto aos três parâmetros de arquitetura da planta analisados: biomassa (ANOVA; $\mathrm{N}=1130 ; \mathrm{R} 2=0,323 ; \mathrm{P}<0,001$ ), número de folhas (ANOVA; $\mathrm{N}=545 ; \mathrm{R} 2=0,391 ; \mathrm{P}<0,001)$ e volume do cone (ANOVA; $\mathrm{N}=545 ; \mathrm{R} 2=0,378 ; \mathrm{P}<0,000)($ Tab. 6 , 7 e 8 ). A biomassa foi o parâmetro que mais variou entre as espécies de bromélia-tanque, seguida do volume do cone e, por último, do número de folhas.

Os dois primeiros eixos da PCA explicaram $61,4 \%$ (eixo 1) e $23,5 \%$ (eixo 2) da variância global dos dados (total 


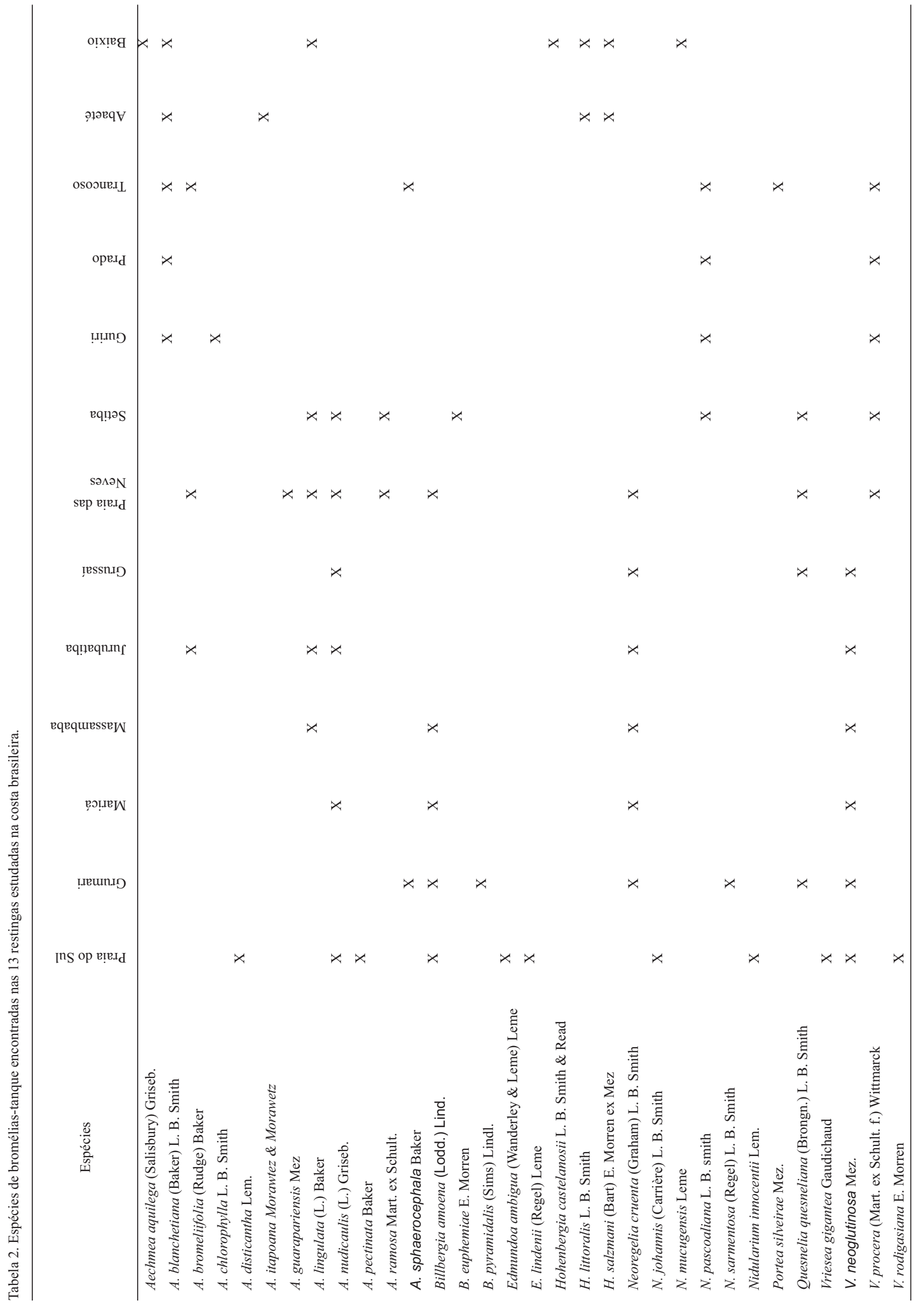




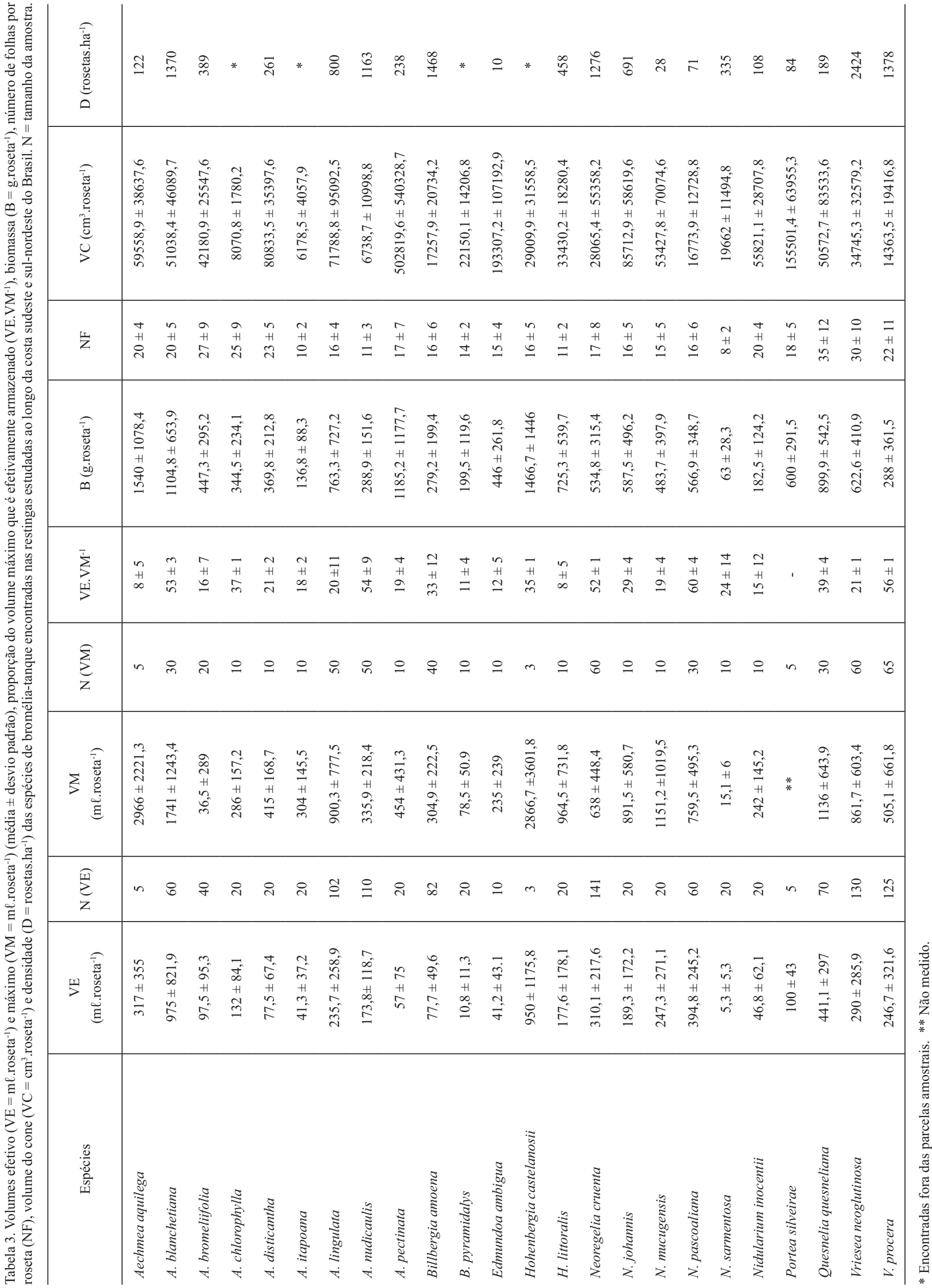


Acta bot. bras. 24(1): 84-95. 2010 .

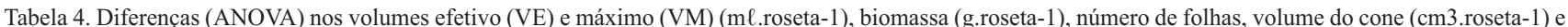
proporção do volume máximo efetivamente armazenado (VE.VM-1) (\%) entre populações de dez espécies de bromélias-tanque encontradas nas restingas do sudeste e sul-nordeste do Brasil. Valores estatisticamente significativos $(\mathrm{P}<0,05)$ em negrito.

\begin{tabular}{|c|c|c|c|c|c|c|}
\hline Espécie & VE & VM & Biomassa & Número de folhas & Volume do cone & Proporção \\
\hline \multirow{3}{*}{ Aechmea blanchetiana } & $N=60$ & $\mathrm{~N}=30$ & $N=60$ & $\mathrm{~N}=30$ & $\mathrm{~N}=30$ & $\mathrm{~N}=30$ \\
\hline & $\mathrm{R}^{2}=0,081$ & $\mathrm{R}^{2}=0,160$ & $\mathrm{R}^{2}=0,020$ & $\mathrm{R}^{2}=0,021$ & $\mathrm{R}^{2}=0,031$ & $\mathrm{R}^{2}=0,073$ \\
\hline & $P=0,089$ & $\mathrm{P}=0,095$ & $P=0,570$ & $P=0,747$ & $\mathrm{P}=0,658$ & $P=0,357$ \\
\hline \multirow{3}{*}{ Aechmea bromeliifolia } & $\mathrm{N}=40$ & $\mathrm{~N}=20$ & $\mathrm{~N}=40$ & $\mathrm{~N}=20$ & $\mathrm{~N}=20$ & $\mathrm{~N}=20$ \\
\hline & $\mathrm{R}^{2}=0,139$ & $\mathrm{R}^{2}=0,325$ & $\mathrm{R}^{2}=0,001$ & $\mathrm{R}^{2}=0,001$ & $\mathrm{R}^{2}=0,017$ & $\mathrm{R}^{2}=0,440$ \\
\hline & $P=0,018$ & $P=0,009$ & $\mathrm{P}=0,867$ & $\mathrm{P}=0,917$ & $\mathrm{P}=0,586$ & $P=0,001$ \\
\hline \multirow{3}{*}{ Aechmea lingulata } & $\mathrm{N}=102$ & $\mathrm{~N}=50$ & $\mathrm{~N}=102$ & $\mathrm{~N}=50$ & $\mathrm{~N}=50$ & $\mathrm{~N}=50$ \\
\hline & $\mathrm{R}^{2}=0,331$ & $\mathrm{R}^{2}=0,256$ & $\mathrm{R}^{2}=0,231$ & $\mathrm{R}^{2}=0,152$ & $\mathrm{R}^{2}=0,209$ & $\mathrm{R}^{2}=0,707$ \\
\hline & $\mathrm{P}<\mathbf{0 , 0 0 1}$ & $\mathbf{P}=\mathbf{0 , 0 0 9}$ & $\mathbf{P}<\mathbf{0 , 0 0 1}$ & $\mathrm{P}=0,108$ & $P=0,029$ & $\mathrm{P}<\mathbf{0 , 0 0 1}$ \\
\hline \multirow{3}{*}{ Aechmea nudicaulis } & $\mathrm{N}=110$ & $\mathrm{~N}=50$ & $\mathrm{~N}=110$ & $\mathrm{~N}=50$ & $\mathrm{~N}=50$ & $\mathrm{~N}=50$ \\
\hline & $\mathrm{R}^{2}=0,301$ & $\mathrm{R}^{2}=0,294$ & $\mathrm{R}^{2}=0,284$ & $\mathrm{R}^{2}=0,271$ & $\mathrm{R}^{2}=0,205$ & $\mathrm{R}^{2}=0,214$ \\
\hline & $\mathrm{P}<0,001$ & $\mathrm{P}=\mathbf{0 , 0 0 3}$ & $\mathrm{P}<0,001$ & $P=0,006$ & $\mathbf{P}=\mathbf{0 , 0 3 2}$ & $\mathbf{P}=\mathbf{0 , 0 1 1}$ \\
\hline \multirow{3}{*}{ Billbergia amoena } & $N=82$ & $\mathrm{~N}=40$ & $N=82$ & $\mathrm{~N}=40$ & $\mathrm{~N}=40$ & $\mathrm{~N}=40$ \\
\hline & $\mathrm{R}^{2}=0,320$ & $\mathrm{R}^{2}=0,392$ & $\mathrm{R}^{2}=0,522$ & $\mathrm{R}^{2}=0,534$ & $\mathrm{R}^{2}=0,413$ & $\mathrm{R}^{2}=0,546$ \\
\hline & $\mathrm{P}<\mathbf{0 , 0 0 1}$ & $\mathrm{P}<0,001$ & $\mathrm{P}<0,001$ & $\mathrm{P}<\mathbf{0 , 0 0 1}$ & $\mathrm{P}<\mathbf{0 , 0 0 1}$ & $\mathrm{P}<0,001$ \\
\hline \multirow{3}{*}{ Neoregelia cruenta } & $\mathrm{N}=141$ & $\mathrm{~N}=60$ & $\mathrm{~N}=141$ & $\mathrm{~N}=60$ & $N=60$ & $N=60$ \\
\hline & $\mathrm{R}^{2}=0,219$ & $\mathrm{R}^{2}=0,064$ & $\mathrm{R}^{2}=0,147$ & $\mathrm{R}^{2}=0,077$ & $\mathrm{R}^{2}=0,518$ & $\mathrm{R}^{2}=0,468$ \\
\hline & $\mathrm{P}<\mathbf{0 , 0 0 1}$ & $P=0,599$ & $P=0,001$ & $P=0,490$ & $\mathbf{P}<\mathbf{0 , 0 0 1}$ & $\mathbf{P}<\mathbf{0 , 0 0 1}$ \\
\hline \multirow{3}{*}{ Neoregelia pascoaliana } & $\mathrm{N}=60$ & $\mathrm{~N}=30$ & $\mathrm{~N}=60$ & $\mathrm{~N}=30$ & $\mathrm{~N}=30$ & $\mathrm{~N}=30$ \\
\hline & $\mathrm{R}^{2}=0,011$ & $\mathrm{R}^{2}=0,056$ & $\mathrm{R}^{2}=0,016$ & $\mathrm{R}^{2}=0,068$ & $\mathrm{R}^{2}=0,133$ & $\mathrm{R}^{2}=0,019$ \\
\hline & $\mathrm{P}=0,733$ & $\mathrm{P}=0,462$ & $P=0,627$ & $\mathrm{P}=0,387$ & $\mathrm{P}=0,145$ & $P=0,768$ \\
\hline \multirow{3}{*}{ Quesnelia quesneliana } & $\mathrm{N}=70$ & $\mathrm{~N}=30$ & $\mathrm{~N}=70$ & $\mathrm{~N}=30$ & $N=30$ & $\mathrm{~N}=30$ \\
\hline & $\mathrm{R}^{2}=0,028$ & $\mathrm{R}^{2}=0,156$ & $\mathrm{R}^{2}=0,188$ & $\mathrm{R}^{2}=0,068$ & $\mathrm{R}^{2}=0,257$ & $\mathrm{R}^{2}=0,392$ \\
\hline & $\mathrm{P}=0,393$ & $\mathrm{P}=0,102$ & $\mathbf{P}=\mathbf{0 , 0 0 1}$ & $\mathrm{P}=0,384$ & $P=0,018$ & $P=0,001$ \\
\hline \multirow{3}{*}{ Vriesea neoglutinosa } & $\mathrm{N}=130$ & $\mathrm{~N}=60$ & $\mathrm{~N}=130$ & $\mathrm{~N}=60$ & $\mathrm{~N}=60$ & $\mathrm{~N}=60$ \\
\hline & $\mathrm{R}^{2}=0,387$ & $\mathrm{R}^{2}=0,117$ & $\mathrm{R}^{2}=0,253$ & $\mathrm{R}^{2}=0,309$ & $\mathrm{R}^{2}=0,474$ & $\mathrm{R}^{2}=0,523$ \\
\hline & $\mathrm{P}<\mathbf{0 , 0 0 1}$ & $\mathrm{P}=0,229$ & $\mathrm{P}<\mathbf{0 , 0 0 1}$ & $\mathbf{P}=\mathbf{0 , 0 0 1}$ & $\mathrm{P}<\mathbf{0 , 0 0 1}$ & $\mathbf{P}<\mathbf{0 , 0 0 1}$ \\
\hline \multirow{3}{*}{ Vriesea procera } & $N=125$ & $\mathrm{~N}=65$ & $\mathrm{~N}=125$ & $N=65$ & $\mathrm{~N}=65$ & $\mathrm{~N}=65$ \\
\hline & $\mathrm{R}^{2}=0,165$ & $\mathrm{R}^{2}=0,223$ & $\mathrm{R}^{2}=0,138$ & $\mathrm{R}^{2}=0,156$ & $\mathrm{R}^{2}=0,153$ & $\mathrm{R}^{2}=0,056$ \\
\hline & $\mathrm{P}<0,001$ & $P=0,004$ & $P=0,001$ & $P=\mathbf{0 , 0 3 5}$ & $\mathbf{P}=\mathbf{0 , 0 3 9}$ & $P=0,479$ \\
\hline
\end{tabular}

Tabela 5. Volumes efetivo (VER) e máximo (VMR) totais por restinga, volume máximo médio por espécie (VMM), densidade (rosetas.ha-1) e riqueza de espécies de bromélias-tanque encontradas nas 13 restingas estudadas da costa brasileira. Letras distintas indicam diferenças significativas entre áreas ( $\mathrm{p} \leq 0,05)$.

\begin{tabular}{|c|c|c|c|c|c|}
\hline Restinga & VER ( $\ell . h a-1)$ & $\operatorname{VMR}\left(\ell \cdot h^{-1}\right)$ & VMM $\left(\ell \cdot\right.$ roseta $\left.^{-1}\right)$ & Densidade & Riqueza \\
\hline Praia do Sul - RJ & $544,3 \mathrm{a}, \mathrm{c}$ & $1964,5 \mathrm{a}, \mathrm{c}$ & 0,358 & 5484 & 11 \\
\hline Grumari - RJ & $170,2 b$ & $590,2 \mathrm{~b}$ & 0,517 & 1141 & 7 \\
\hline Maricá - RJ & $4353,4 a$ & $9639,5 \mathrm{a}$ & 0,712 & 13530 & 4 \\
\hline Massambaba - RJ & $225,1 \mathrm{a}$ & $5535,3 \mathrm{a}$ & 0,884 & 6263 & 4 \\
\hline Jurubatiba - RJ & $1604,3 \mathrm{a}$ & $4513,1 \mathrm{a}$ & 0,547 & 7055 & 5 \\
\hline Grussaí - RJ & $1060,1 \mathrm{a}, \mathrm{d}$ & $1681,7 \mathrm{a}, \mathrm{d}$ & 0,414 & 4062 & 4 \\
\hline Praia das Neves - ES & $935,6 a, c$ & $2274,2 \mathrm{a}, \mathrm{c}$ & 0,613 & 3710 & 9 \\
\hline Setiba - ES & $1151,3 \mathrm{a}$ & $2107,1 \mathrm{a}$ & 0,514 & 3865 & 7 \\
\hline Guriri - ES & $600,9 a, c$ & $781,2 \mathrm{a}, \mathrm{c}$ & 1,178 & 576 & 4 \\
\hline Prado - BA & $3255,6 a, b$ & $7022,0 \mathrm{a}, \mathrm{b}$ & 2,140 & 3283 & 3 \\
\hline Trancoso-BA & $2801,9 \mathrm{a}, \mathrm{d}$ & $6172,4 \mathrm{a}, \mathrm{d}$ & 0,952 & 6236 & 6 \\
\hline Abaeté - BA & $142,3 \mathrm{a}$ & $772,6 \mathrm{a}$ & 0,863 & 895 & 4 \\
\hline Baixio - BA & $155,6 \mathrm{a}$ & $1334,7 \mathrm{a}$ & 1,171 & 1140 & 7 \\
\hline TOTAL & $1307,7 \mathrm{a}$ & $3414,5 \mathrm{a}$ & - & 4402 & - \\
\hline
\end{tabular}




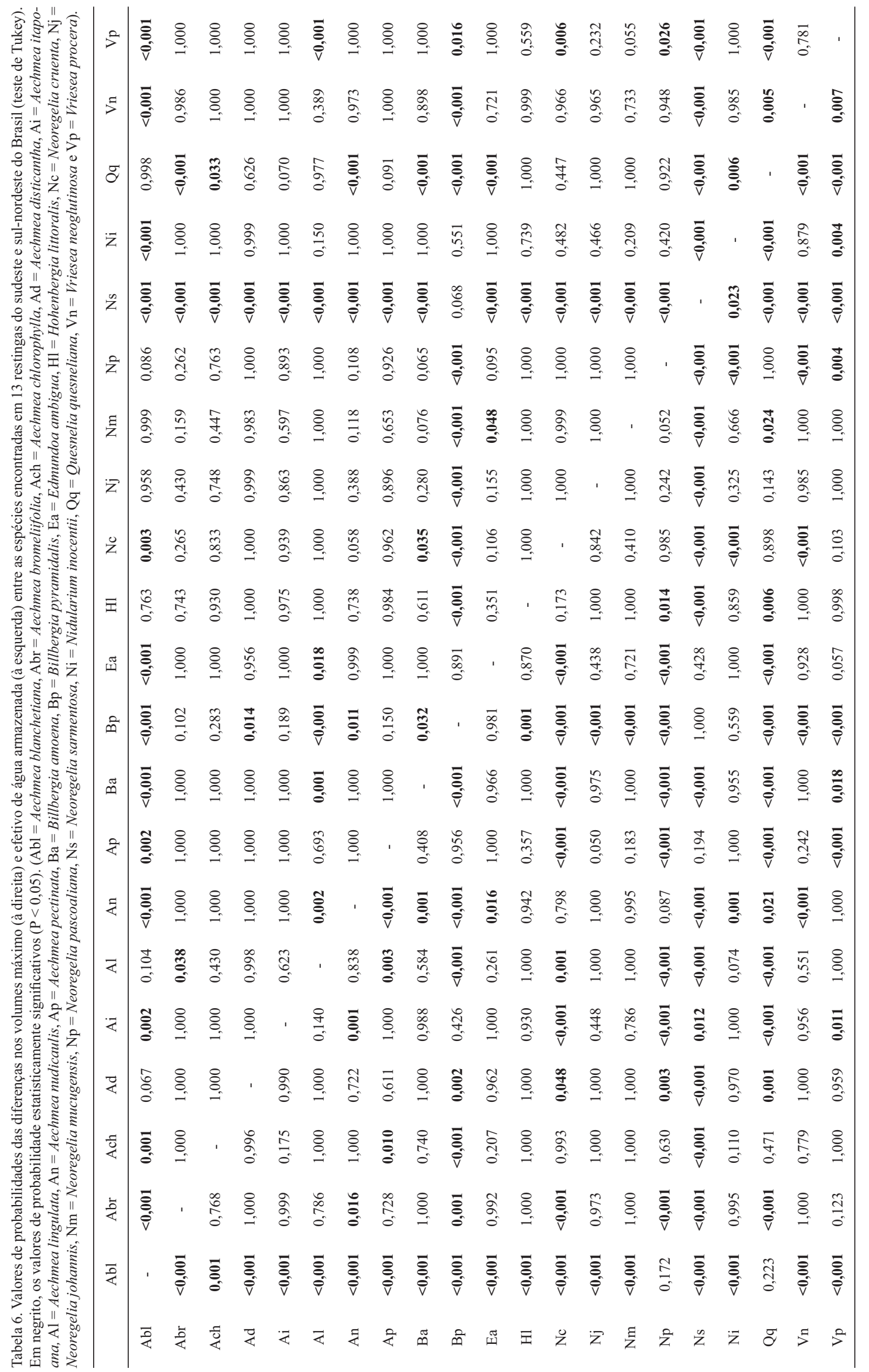




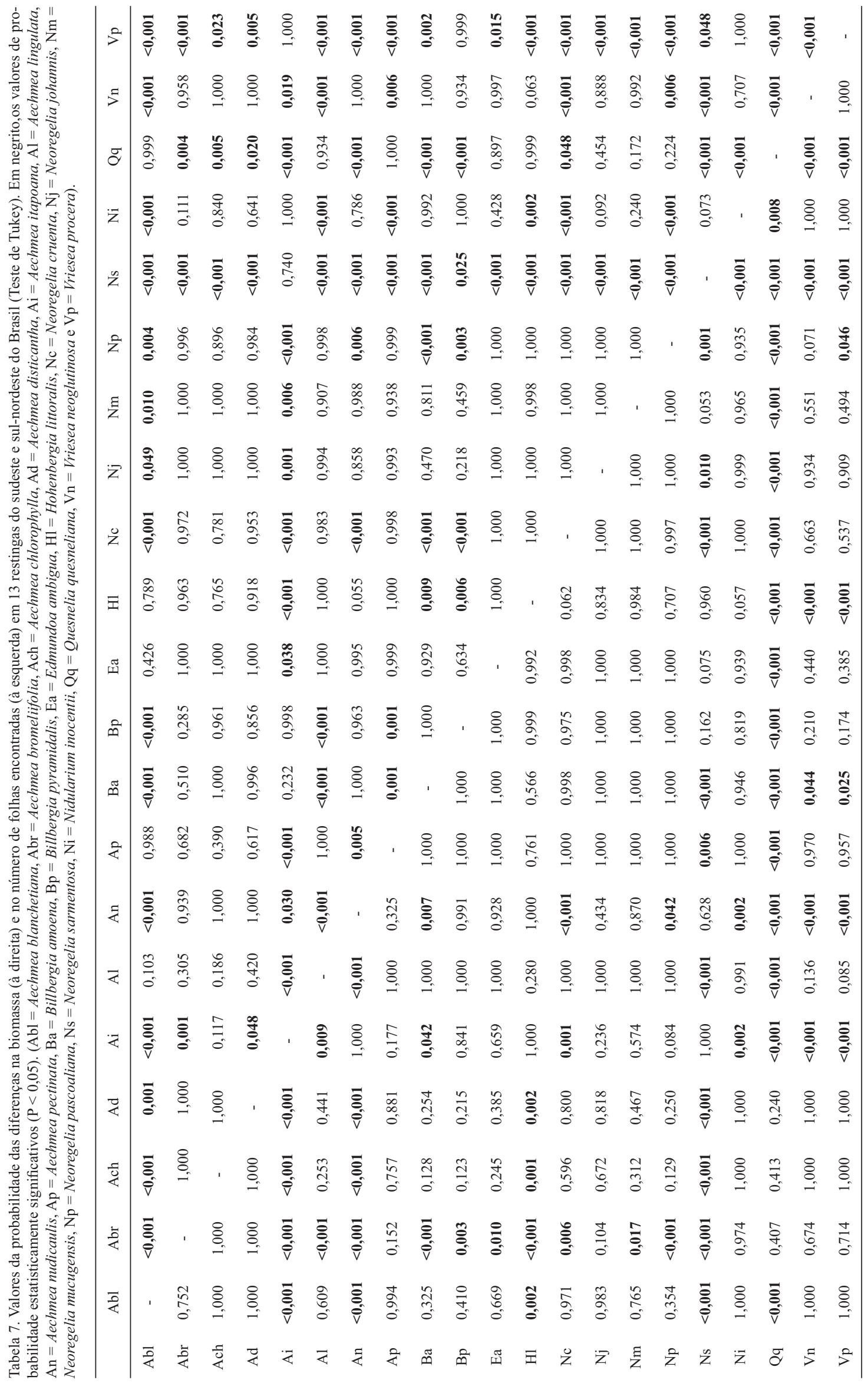




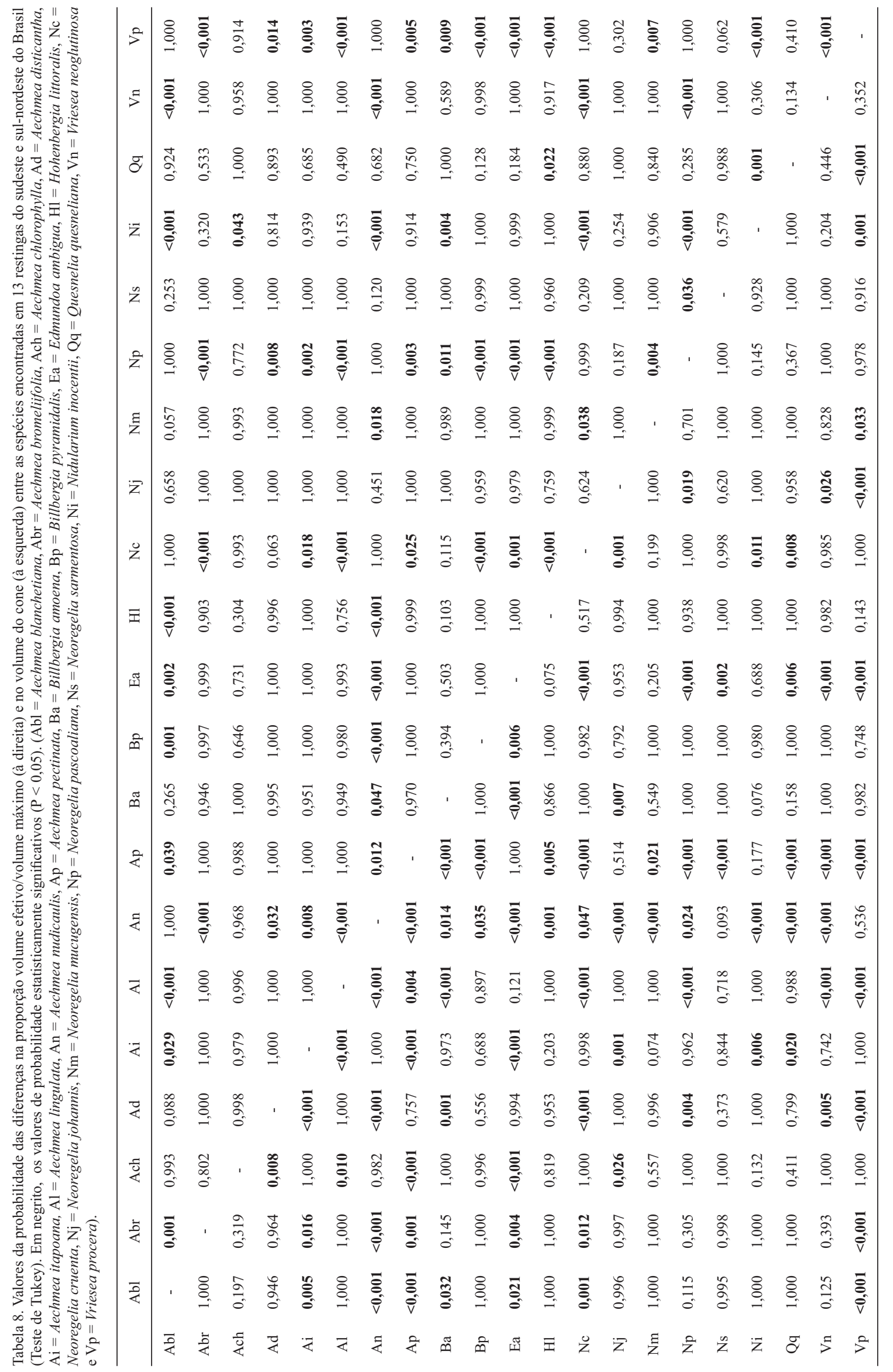




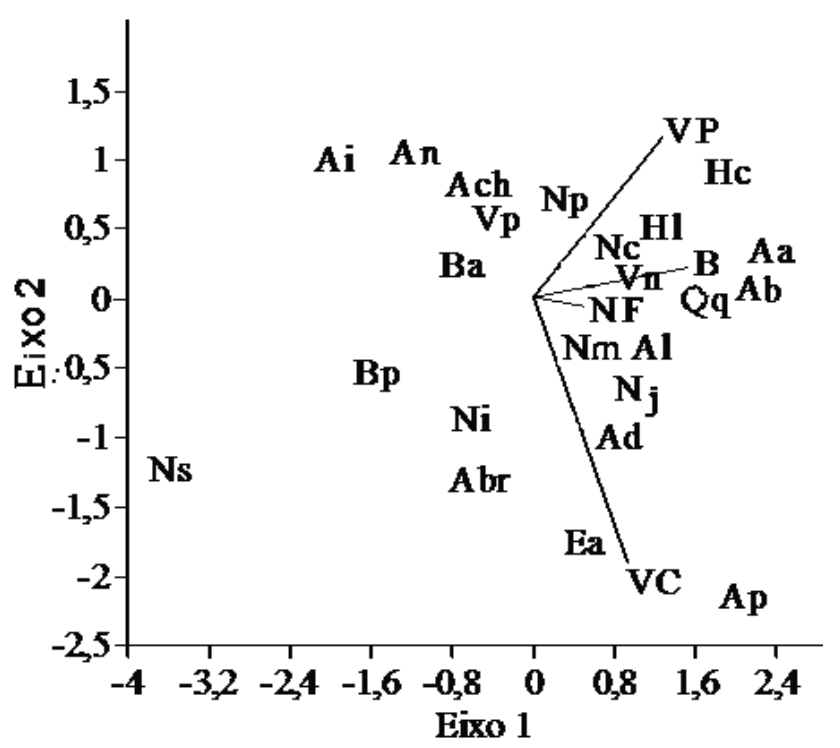

Figura 1. Diagrama de ordenação das espécies baseado nas variáveis morfométricas médias destas espécies em 13 restingas da costa brasileira. $\mathrm{Abl}=$ Aechmea blanchetiana, $\mathrm{Abr}=$ Aechmea bromeliifolia, $\mathrm{Ach}=$ Aechmea chlorophylla, $\mathrm{Ad}$ $=$ Aechmea disticantha, $\mathrm{Ai}=$ Aechmea itapoana, $\mathrm{Al}=$ Aechmea lingulata, $\mathrm{An}$ $=$ Aechmea nudicaulis, $\mathrm{Ap}=$ Aechmea pectinata, $\mathrm{Ba}=$ Billbergia amoena, $\mathrm{Bp}$ $=$ Billbergia pyramidalis, $\mathrm{Ea}=$ Edmundoa ambigua, $\mathrm{Hl}=$ Hohenbergia littoralis, $\mathrm{Nc}=$ Neoregelia cruenta, $\mathrm{Nj}=$ Neoregelia johannis, $\mathrm{Nm}=$ Neoregelia mucugensis, $\mathrm{Np}=$ Neoregelia pascoaliana, $\mathrm{Ns}=$ Neoregelia sarmentosa, $\mathrm{Ni}=$ Nidularium inocentii, $\mathrm{Qq}=$ Quesnelia quesneliana, $\mathrm{Vn}=$ Vriesea neoglutinosa $\mathrm{e} \mathrm{Vp}=$ Vriesea procera $; \mathrm{B}=$ biomassa $\mathrm{NF}=$ número de folhas; $\mathrm{VC}=$ volume do cone; $\mathrm{VP}=$ volume máximo de água.

acumulado: $84,9 \%$ ). A PCA também indicou que as quatro variáveis morfométricas utilizadas apresentaram elevados valores de correlação com o primeiro eixo $(\mathrm{B}=0,963$; VP $=0,839 ; \mathrm{VC}=0,613 ; \mathrm{NF}=0,503)$. A ordenação, no entanto, mostra que grande parte das espécies estão agrupadas segundo o VP e B, e que um outro grupo está agrupado especialmente pelo VC.

Apesar disso, algumas espécies não parecem agrupar-se segundo as variáveis morfométricas (Fig. 1). Não encontramos correlação entre a pluviosidade média de cada restinga e os valores obtidos de VER $(R=-0,179), \operatorname{VRM}(R=-0,349)$ e VMM $(\mathrm{R}=-0,165)$.

Houve uma relação significativa entre a densidade de bromélias-tanque na restinga e o volume total de água efetivamente armazenada em bromélias nas respectivas restingas (análise de regressão; $\mathrm{N}=13 ; \mathrm{R}^{2}=0,517 ; \mathrm{F}_{1,11}=11,787$; $\mathrm{P}=0,006)$. Dentre as restingas analisadas, Prado foi a que possuiu o maior VM de água por bromélia, com cerca de 2 $\ell$.roseta ${ }^{-1}$, seguida pelas restingas de Guriri $\left(1,178\right.$ $\ell$.roseta $\left.{ }^{-1}\right)$ e Baixio $\left(1,171\right.$ l.roseta $\left.{ }^{-1}\right)$.

\section{Discussão}

Nossos dados indicam que, nos ambientes de restinga, as bromélias podem armazenar (e, conseqüentemente, disponibilizar para outros organismos) uma considerável quantidade de água livre (em média, cerca de $3.400 \ell$ de água por hectare). Como as restingas são caracterizadas como habitats com restrição de água livre, elevada salinidade e solos pobres em nutrientes (Van Der Valk 1974; Waechter 1985; Henriques et al.1986), as espécies animais e vegetais que vivem neste ambiente estão sujeitas aos efeitos limitantes de seus fatores ambientais, que podem restringir a manutenção de suas populações (Franco et al. 1984; Henriques et al. 1984; Araújo et al. 1998). Nessas condições, as bromélias podem representar um microhabitat relativamente estável, já que os tanques tendem a permanecer com água mesmo durante períodos de seca (Krügel \& Richter 1995), o que favorece o desenvolvimento de um grande número de organismos (Oliveira et al. 1994). Desta forma, a capacidade das bromélias de reservar água livre as torna uma importante fonte de recurso hídrico para outros organismos (Picado 1913; Benzing 1990; Lopez 1998; Rocha et al. 2000), o que é de especial importância em ambientes como as restingas (Alves et al. 1996).

Os dados deste estudo mostram que as espécies de bromélias com maior capacidade de reservar água (maiores valores de volume máximo) foram, de forma geral, aquelas com maior biomassa e maior número de folhas por roseta. Desta forma, nossos dados indicam que a morfologia externa da planta constitui um importante fator que tende a alterar o volume máximo de água armazenada pelas diferentes espécies de bromélia-tanque, em função do tamanho do tanque.

Entre bromélias de uma mesma espécie, o volume máximo de água armazenada nos tanques pode variar tanto devido a fatores intrínsecos à espécie (idade da planta e o tamanho da roseta), quanto a fatores extrínsecos inerentes ao habitat em que vive a bromélia (condições ambientais, como pluviosidade, taxas de insolação e de evaporação) (Benzing 1980). Bromélias de uma mesma espécie vivendo em ambientes com disponibilidades diferentes de nutrientes, água, temperatura e luz podem desenvolver fenótipos distintos (Benzing 1980; Medina et al. 1986; Cogliatti-Carvalho et al. 1998) e essa flexibilidade fenotípica pode alterar a capacidade individual de armazenamento de água, já que altera o tamanho das folhas e a forma geral das rosetas (Cogliatti-Carvalho et al. 1998). Desta forma, bromélias de uma mesma espécie e de uma mesma idade podem armazenar volumes de água diferentes se possuírem fenótipos e/ou se estiverem em ambientes distintos (Richardson 1999). As populações de A. bromeliifolia, A. lingulata, A. nudicaulis, B. amoena e $V$. procera, amostradas neste estudo, em diferentes áreas, diferiram estatisticamente no volume máximo de água armazenada, provavelmente por apresentarem fenótipos distintos, como conseqüência das diferentes condições abióticas a que estão submetidas em cada restinga. Nas demais espécies em que houve diferença entre populações nos valores de VM, houve também diferença significativa no volume do cone. No entanto, nem todas as espécies cujo volume do cone diferiu entre populações também diferiram no VM.

O VE de água encontrado nas rosetas das restingas estudadas foi estatisticamente diferente tanto entre as áreas como entre as espécies de Bromeliaceae. Estes valores podem variar não somente devido às diferenças morfológicas entre espécies 
(número de folhas, tamanho da bromélia e forma da roseta), na densidade de rosetas e composição de espécies (com diferentes formas e tamanhos de roseta), mas também, devido às condições abióticas características de cada restinga (índice de pluviosidade, taxas de insolação e evaporação, e grau de sombreamento causado pela cobertura vegetal). Estes fatores provavelmente atuam conjuntamente, resultando na observada diferença no volume efetivo de água armazenada pelas diferentes espécies de bromélias-tanque em diferentes ambientes (e.g. Laessle 1961; Teixeira et al. 1997; Zotz \& Thomas 1999).

As diferenças encontradas entre espécies nas proporções VE.VM-1 podem se dever especialmente a fatores relacionados à morfologia da planta, mais especificamente, à razão entre o diâmetro e a altura, que afetam a taxa de evaporação da água armazenada nos tanques central e laterais (Lopez, 1998). Por exemplo, espécies como E. ambigua e $N$. johannis, que possuem rosetas mais abertas, tendem a apresentar um baixo volume efetivo de água, uma vez que, a água armazenada supostamente sofre uma maior taxa de evaporação devido ao maior grau de exposição ao ar e à luz (Lopez 1998). Por outro lado, espécies que possuem rosetas de formato tubular (e.g. mais fechadas como A. nudicaulis), apesar de possuírem uma menor área para captação de água da chuva, possuem uma menor relação superfície.volume-1, o que, supostamente, reduz a taxa de evaporação da água armazenada na roseta, resultando em que estas espécies possuam um maior volume efetivo de água armazenada.

As diferenças encontradas no VE e no VM em broméliastanque entre as diferentes restingas podem estar relacionadas à densidade e ao tamanho médio das espécies de broméliastanque encontradas em cada restinga, parâmetros que, de forma geral, variam entre áreas (ver Araújo 1992; 2000; Cogliatti-Carvalho et al. 2000; 2001; Henriques et al. 1984; 1986). Em geral, as restingas em que ocorreram os maiores VE de água no interior de bromélias, concomitantemente ocorreram os maiores valores de VM e de densidade de rosetas de bromélias-tanque, como é o caso de Maricá, Trancoso, Massambaba e Jurubatiba. Isto significa que, quanto maior a densidade de bromélias-tanque em uma restinga, maiores são os VE e VM totais de água armazenada nas bromélias, o que reforça a idéia de que as bromélias-tanque constituem importantes reservatórios de água livre nestes ambientes.

No entanto, a composição de espécies de bromélias também tem um efeito sobre a quantidade de água disponível em uma determinada restinga. Por exemplo, em algumas restingas, apesar do número e da densidade de bromélias-tanque serem relativamente menores do que em outras, o VE e o VM são elevado, como ocorreu em Prado. Isto provavelmente se deve ao fato das espécies de bromélias-tanque presentes nesta restinga serem de grande porte (ou seja, apresentarem biomassa e volume do cone elevados), em geral maior do que em outras localidades, permitindo que um grande volume de água possa ser armazenado e esteja disponível no tanque dessas plantas.

Em termos das diferenças interespecíficas em parâmetros como VM, B, NF e VC das bromélias, os dados indicam que as espécies de bromélia amostradas se agrupam segundo semelhanças na morfologia das rosetas. As bromélias que foram agrupadas segundo os parâmetros de $\mathrm{B}$ e de NF foram aquelas que ocorreram em maior abundância no solo descoberto das restingas (Henriques et al. 1986; CogliattiCarvalho et al. 2001), um ambiente caracterizado por alta intensidade de luz e temperatura elevada (Henriques et al. 1984). Estas condições ambientais favorecem a perda de água por evaporação e, não coincidentemente, as espécies agrupadas possuem, comparativamente, baixo VE, apesar de possuírem tanques robustos capazes de reter grande quantidade de água da chuva, ou seja, um VM alto. Outro conjunto de espécies foi ordenado segundo o VC, neste grupo foram agrupadas as espécies de menor porte, menor VM e ciófilas, ou seja, aquelas encontradas em zonas sombreadas das restingas (formações de vegetação arbustiva e florestal ou dentro de moitas), um ambiente comparativamente menos ensolarado e com temperatura mais baixa (Franco et al. 1984), onde a necessidade de desenvolvimento de tanques capazes de armazenar grandes quantidades de água é supostamente menor. Algumas espécies como A. itapoana, A. nudicaulis, B. pyramidalis e $N$. sarmentosa não foram agrupadas de acordo com os parâmetros analisados.

Concluímos que as bromélias-tanque constituem importantes fontes de água livre no ecossistema de restinga, sendo variáveis o volume de água que cada espécie armazena e o volume total disponível nas rosetas das bromélias, nas diferentes restingas. Nossos dados apontam para o fato de que a quantidade total de água que pode ser reservada em um ambiente de restinga no interior de bromélias-tanque é elevada e resulta não apenas das condições climatológicas do ambiente local, mas também da composição da comunidade de bromeliáceas da área.

\section{Agradecimentos}

Este estudo é parte da tese de Doutorado do primeiro autor no Programa de Pós-Graduação em Ecologia da UFRJ, dentro do Projeto Ecologia de Restingas Brasileiras, do Programa de Ecologia, Conservação e Manejo de Ecossistemas do Sudeste Brasileiro do Departamento de Ecologia, Instituto de Biologia Roberto Alcântara Gomes, da Universidade do Estado do Rio de Janeiro. Este estudo foi parcialmente subvencionado através de Auxílio à Pesquisa da Fundação de Amparo à Pesquisa do Estado do Rio de Janeiro (FAPERJ, Processo No. E-26/171.885/1999), com Auxílio à Pesquisa do Conselho Nacional do Desenvolvimento Científico e Tecnológico - CNPq (Processo No. 46.1970/00-7) para o último autor e parcialmente pelo Programa de Pesquisas Ecológicas de Longa Duração (PELD/CNPq). Agradecemos a Idea Wild pelo apoio financeiro; a Monique Van Sluys pela revisão crítica do texto e Elton Leme e Andréa Costa identificaram as espécies de bromeliáceas. Ao CNPq (processos No._307653/2003-0, 477715/2006-0 e 140727/1999-0), Coordenação de Aperfeiçoamento de Pessoal de Ensino Superior - CAPES (processo No. 990207-7) e FAPERJ (processo E-26/100.471.2007).

\section{Referências bibliográficas}

Alves, M.A.S.; Rocha, C.F.D. \& Van-Sluys, M. 1996. Recomposição de uma população de Vriesea neoglutinosa 15 meses após uma queimada. Bromélia 3(4): 3-8.

Araújo, D.S.D. 1992. Vegetation types of sandy coastal plains of Tropical Brazil: a first approximation. Pp. 337-347. In: Coastal Plant Communities of Latin America. New York, Academic Press. 
Araújo, D.S.D. \& Oliveira, R. 1988. Reserva Biológica Estadual da Praia do Sul (Ilha Grande, Estado do Rio de Janeiro): lista preliminar da flora. Acta Botanica Brasilica 1: 83-94.

Araújo, D.S.D.; Scarano, F.R.; Sá, C.F.C.; Kurtz, B.C.; Zaluar, H.L.T.; Montezuma, R.C.M. \& Oliveira, R.C. 1998. Comunidades vegetais do Parque Nacional da Restinga de Jurubatiba. Pp. 39-62. In: F.A. Esteves (ed.). Ecologia das lagoas costeiras do Parque Nacional da Restinga de Jurubatiba e do Município de Macaé (RJ). NUPEM, Universidade Federal do Rio de Janeiro.

Assumpção, J. \& Nascimento, M.T. 2000. Estrutura e composição florística de quatro formações vegetais de restinga no complexo lagunar Grussaí/Iquipari, São João da Barra, RJ, Brasil. Acta Botanica Brasilica 14(3): 301-315.

Benzing, D.H. 1980. The biology of bromeliads. California, Mad River Press.

Benzing D.H. 1990. Vascular epiphytes. Cambridge, Cambridge University Press.

Benzing, D.H. \& Renfrow, A. 1974. The mineral nutrition of Bromeliaceae. Botanical Gazete 135(4): 281-288.

Cerqueira, R. 2000. Biogeografia de Restingas. Pp. 65-75. In: F.A. Esteves e L.D. Lacerda (eds.). Ecologia de Restingas e Lagoas costeiras, NUPEM/UFRJ. Rio de Janeiro, Universidade Federal do Rio de Janeiro.

Cogliatti-Carvalho, L.; Almeida, D.R. \& Rocha, C.F.D. 1998. Phenotypic response of Neoregelia johannis (Bromeliaceae) dependent on light intensity reaching the plant microhabitat. Selbyana 19(2): 240-244.

Cogliatti-Carvalho, L.; Freitas, A.F.N.; Pessôa, T.C.R. \& Rocha, C.F.D. 2000 Parâmetros da Ecologia da Comunidade de Bromeliaceae em cinco zonas de vegetação da Restinga de Setiba, ES. Pp. 20-30. In: Anais do V Simpósio de Ecossistemas Brasileiros. v.3. São Paulo, ACIESP.

Cogliatti-Carvalho, L.; Freitas, A.F.N.; Rocha, C.F.D. \& Van-Sluys, M. 2001. Variação na estrutura e na composição de Bromeliaceae em cinco zonas de restinga do Parque Nacional da Restinga de Jurubatiba, Macaé, RJ. Revista Brasileira de Botânica 24(1): 1-9.

FIDERJ. 1978. Indicadores Climatológicos do Estado do Rio de Janeiro. Rio de Janeiro, FIDERJ.

Franco, A.C.; Valeriano, D.M.; Santos, F.M.; Hay, J.D.; Henriques, R.P.B. \& Medeiros, R.A. 1984. Os microclimas das zonas de vegetação da praia da restinga de Barra de Maricá, Rio de Janeiro. Pp. 413-425. In: L.D. Lacerda, D.S.D. Araújo, R. Cerqueira \& B. Turcq (orgs.). Restingas: Origem, estrutura e processos. Niterói, CEUFF.

Freitas, A.F.N., Cogliatti-Carvalho, L., Sluys, M.V. \& Rocha, C.F.D. 2000. Distribuição espacial de bromélias na restinga de Jurubatiba, Macaé, RJ. Acta Botanica Brasilica 14(2): 175-180.

Henriques, R.P.B.; Meirelles, M.L. \& Hay, J.D. 1984. Ordenação e distribuição de espécies das comunidades vegetais na praia da restinga de Barra de Maricá, Rio de Janeiro. Revista Brasileira de Botânica 7: 27-36.

Henriques, R.P.B.; Araújo, D.S.D. \& Hay, J.D. 1986. Descrição e classificação dos tipos de vegetação da restinga de Carapebus, Rio de Janeiro. Revista Brasileira de Botânica 9: 173-189.

Krügel, P. \& Richter, S. 1995. Syncope antenori - a bromeliad breeding frog with free-swimming, nonfeeding tadpoles (Anura, Microhylidae). Copeia 95(4): 955-963.

Laessle, A.M. 1961. A micro-limnological study of Jamaican bromeliads. Ecology 42(3): 499-517.

Legendre, P. \& Legendre, L. 1998. Numerical Ecology. Elsevier Science B.V., Amsterdam.

Lopez, L.C.S.; D’Elias, A. \& Iglesias-Rios, R. 1998. Fatores que Controlam a Riqueza e a Composição da Fauna Aquática em Tanques de Bromélia Aechmea bromellifolia na Restinga de Jacarepiá-Saquarema (RJ). Pp. 91-100. In: J.L.Nessimian, A.L. Carvalho. (orgs.). Ecologia de Insetos Aquáticos. Rio de Janeiro, Computer \& Publish Editoração Ltda.

Medina, E. 1974. Dark CO fixation, habitat preference and evolution within the Bromeliaceae. Evolution 28: 677-686.

Medina, E.; Olivares, E. \& Diaz, M. 1986. Water stress and light intensity effects on growth and nocturnal acid accumulation in a terrestrial
CAM bromeliad (Bromelia humilis Jacq.) under natural conditions. Oecologia 70: 441-446.

Morelatto, L.P.C. 2000. Introduction: the Brazilian Atlantic Forest. Biotropica 32(4b): 786-792.

Nunes-Freitas, A.F., Rocha-Pessôa, T.C., Cogliatti-Carvalho, L. \& Rocha, C.F.D. 2006. Bromeliaceae da restinga da Reserva Biológica Estadual da Praia do Sul: composição, abundância e similaridade da comunidade. Acta Botanica Brasilica 20(3): 709-717.

Oliveira, M.G.N.; Rocha, C.F.D. \& Bagnall, T. 1994. A comunidade animal associada à bromélia-tanque Neoregelia cruenta (R. Graham) L. B. Smith. Bromélia 1(1): 22-29.

Pereira, O.J. 1990. Caracterização fitofisionômica da restinga de Setiba, Guarapari, ES. Pp. 207-219. In Anais do II Simpósio Ecossistemas da Costa sul-sudeste Brasileira. v.3. São Paulo, ACIESP.

Picado, C. 1913. Les broméliacées épiphytes considérées comme milieu biologique. Bulletin Scientifique France et Belgique 5: 215-360.

Richardson, B.A. 1999. The bromeliad microcosm and the assessment of faunal diversity. In a neotropical forest. Biotropica 31(2): 312-336.

Rizzini, C.T. 1979. Tratado de Fitogeografia da Brasil. Aspectos sociológicos e florísticos. São Paulo, Hucitec.

Rocha, C.F.D.; Cogliatti-Carvalho, L.; Almeida, D.R. \& Freitas, A.F.N 2000. Bromeliads: Biodiversity amplifiers. Journal of Bromeliad Society 50(2): 81-83

Rocha, C.F.D.; Cogliatti-Carvalho, L.; Nunes-Freitas, A.F.; Rocha-Pessôa, T.C.; Dias, A.S.; Ariani, C.V. \& Morgado, L.N. 2004. Conservando uma larga porção da diversidade biológica através da conservação de Bromeliaceae. Vidália 2(1): 52-72.

Rocha-Pessôa, T.C., Nunes-Freitas, A.F., Cogliatti-Carvalho, L. \& Rocha, C.F.D. 2008. Species composition of Bromeliaceae and their distribution at the Massambaba Restinga in Arraial do Cabo, Rio de Janeiro, Brazil. Brazilian Journal of Biology 68(2): 251-257.

Scarano, F.R. 2002. Structure, Function and Floristic relationships of plant communities in stressful habitats marginal to the Brazilian Atlantic Rainforest. Annals of Botany 90: 517-524.

Silva, A.L.G. \& Pinheiro, M.C.B. 2007. Biologia floral e da polinização de quatro espécies de Eugenia L. (Myrtaceae). Acta Botanica Brasilica 21(1): 235-247.

Silva, J.G. \& Oliveira, A.S. 1989. A vegetação de restinga do Município de Maricá, RJ. Acta Botanica Brasilica 3(2): 253-272.

Silva, J.G. \& Somner, G.V. 1984. A vegetação de restinga na Barra de Maricá, RJ. Pp. 217-225. In: L.D. Lacerda, D.S.D. Araújo, R. Cerqueira \& B. Turcq (orgs). Restingas: origem, estrutura, processos. Niterói, CEUFF.

Teixeira, R.L.; Zamprogno, C.; Almeida, G.I. \& Schineider, J.A.P. 1997. Tópicos ecológicos de Phyllodytes luteolus (Amphibia, Hylidae) da restinga de Guriri, São Mateus - ES. Revista Brasileira de Biologia 57(4): 647-654.

ter Braak, C.J.F. 1987. The analysis of vegetation-environment realtionships by canonical correspondence analysis. Vegetatio 69(1): 69-67.

ter Braak, C.J.F. 1995. Ordenation. Pp. 91-173. In: R.H.G. Jongman, C.J.F. ter Braak \& O.F.R. van Tongeren (eds.). Data analysis in community and landscape ecology. Cambridge, Cambridge University Press.

Van Der Valk, A.G. 1974. Environmental factors controlling the distribution of forbs on coastal foredune in Cape Hatteras National Seashore. Cannadian Journal of Ecology 52: 1057-1073.

Waechter, J.L. 1985. Aspectos ecológicos da vegetação de restinga no Rio Grande do Sul, Brasil. Comunidade do Museu Científico. PUCRS, Série Botânica, Porto Alegre 33: 49-68.

Zaluar, H.L.T. \& Scarano, F.R. 2000. Facilitação em restingas de moitas: um século de buscas por espécies focais. Pp.03-23. In: F.A. Esteves \& L.D. Lacerda (eds.). Ecologia de Restingas e Lagoas costeiras, NUPEM/ UFRJ. Rio de Janeiro, Universidade Federal do Rio de Janeiro.

Zar, J.H. 1999. Biostatistical analysis. New Jersey, Prentice Hall.

Zotz, G. \& Thomas, V. 1999. How much water is in the tank? Model calculations for two epiphytic bromeliads. Annals of Botany 83: 183-192. 